\section{Scientific journal}

\section{PHYSICAL AND MATHEMATICAL EDUCATION}

Has been issued since 2013.

Науковий журнал

ФІЗИКО-МАТЕМАТИЧНА ОСВІТА

Видається з 2013
ISSN 2413-158X (online)

ISSN 2413-1571 (print)

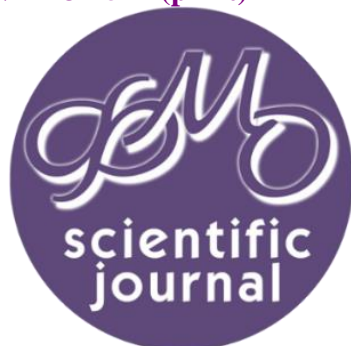

Іщенко Р.М., Горбунович І.В. Ефективність дистанційного навчання фізики студентів технічних спеціальностей в умовах карантину. Фізико-математична освіта. 2021. Випуск 3(29). С. 63-67.

Ishchenko R., Gorbunovich I. Effectiveness of distance learning of physics of technical specialties students under quarantine conditions. Physical and Mathematical Education. 2021. Issue 3(29). P. 63-67.

DOI 10.31110/2413-1571-2021-029-3-010

Удк378.1; 378.9

Р.М. Іщенко

Національний транспортний університет, Україна rm_ischenko@ukr.net ORCID: 0000-0003-0158-4020

І.В. Горбунович

Начіональний транспортний університет, Україна irina.gorbunovich@gmail.com ORCID: 0000-0002-6859-0663

\title{
ЕФЕКТИВНІСТЬ ДИСТАНЦІЙНОГО НАВЧАННЯ ФІЗИКИ СТУДЕНТІВ ТЕХНІЧНИХ СПЕЦІАЛЬНОСТЕЙ В УМОВАХ КАРАНТИНУ
}

\section{АНОТАЦІЯ}

Формулювання проблеми. У сучасному світі особливої актуальності набуває дистанційна форма навчання, під час якої освітній процес здійснюється шляхом використання сучасних інформаційно-комунікаційних технологій. Фізика, як відомо, відноситься до циклу обов'язкових навчальних дисциплін природничо-наукової і математичної підготовки, що вивчається студентами технічних спечіальностей. У той же час фізика є традиційно однією з найскладніших дисциплін для більшості студентів. Відповідно, дослідження ефективності дистанційного навчання фізики студентів технічних спеціальностей в умовах карантину є актуальним.

Матеріали і методи. Опрацьовано результати успішності студентів технічних спеціальностей Національного транспортного університету з фізики за результатами очного та дистанційного навчання. Кількість студентів складала 242 особи. Для досягнення поставленої мети роботи використовувалися наступні методи: аналіз і систематизація - під час огляду наукових публікацій за обраною тематикою дослідження; аналіз, синтез, порівняння, систематизація, узагальнення - під час обробки та обговорення результатів успішності студентів з фізики за результатами очного та дистаниійного навчання.

Результати. У представленій роботі виявлено, що розподіл підсумкових оцінок студентів з фізики за результатами очного та дистанційного навчання досить відрізняється. Зокрема, за результатами дистанційного навчання фізики можна виділити дві найбільші підгрупи студентів, що отримали максимальні (A) та, відповідно, мінімальні (Е) підсумкові оцінки. Така тенденція спостерігалася в кожній академічній групі студентів. Рівень якості навчання, тобто відсоток студентів, що отримали з фізики підсумкові очінки А, В іС, під час дистанційного навчання дорівнював $50.8 \%$ і виявився на $5.8 \%$ вищим, ніж під час очного навчання.

Висновки. Таким чином, дистанційна форма навчання фізики студентів технічних спеціальностей під час карантину з достатньою ефективністю замінила очну форму навчання. Однак, дистанційне навчання фізики у сучасному форматі виявилося менш придатним для студентів з низьким рівнем самоорганізації. Зазначені студенти виявилися психологічно неготовими до дистанційного навчання та, відповідно, отримали мінімальні підсумкові оцінки з фізики. В подальшому, на думку авторів, більш ефективною може бути змішана форма навчання фізики.

КЛЮчОВІ СЛОВА: дистанційна форма навчання, очна форма навчання, курс фізики, підсумкові оцінки з фізики, ефективність дистанційного навчання, студенти технічних спеціальностей.

\section{ВСТУП}

Постановка проблеми. Останнім часом все більшої актуальності набуває дистанційна форма навчання, яка надає можливість студентам брати участь в освітньому процесі віддалено від закладу вищої освіти (ЗВО) в будь-який зручний час. Освітній процес під час зазначеної форми навчання здійснюється шляхом використання сучасних інформаційнокомунікаційних технологій. Дистанційне навчання, що здійснюється з використанням стаціонарних персональних комп'ютерів і ноутбуків, називають електронним навчанням (E-learning). Модифікацією електронного навчання $\epsilon$ мобільне навчання (M-learning), тобто дистанційне навчання з використанням смартфонів, планшетів, електронних книг

(C) Р.М. Іщенко, І.В. Горбунович, 2021. 
тощо. Розвиток дистанційної форми навчання в ЗВО забезпечує рівний доступ усіх бажаючих до отримання вищої освіти. Особливої актуальності дистанційна форма навчання набула під час пандемії COVID-19, під час якої, за даними ЮНЕСКО, 91 \% учнів та студентів по всьому світу опинилися на карантині. Таке глобальне закриття закладів загальної середньої освіти та ЗВО є першим з часів Другої світової війни (Андрущенко, 2020).

Як відомо, фізика відноситься до циклу обов'язкових навчальних дисциплін природничо-наукової і математичної підготовки, що вивчається студентами технічних спеціальностей ЗВО. Загальні та професійні компетентності, набуті під час вивчення курсу фізики, сприяють формуванню наукового світогляду й наукового стилю мислення студентів та $€$ основою для подальшого успішного опанування більшості загальнотехнічних і фахових навчальних дисциплін. У той же час фізика $€$ традиційно однією з найскладніших дисциплін для більшості студентів першого курсу (Іщенко \& Ісаєнко, 2020). Проблеми, що виникають під час вивчення фізики, а також дисциплін математичного циклу, є одними з головних причин низької успішності студентів-першокурсників. Відповідно, дослідження ефективності дистанційного навчання фізики студентів технічних спеціальностей в умовах, що склалися, $є$ актуальним.

Аналіз актуальних досліджень. Побудовою теорій та розробкою технологій дистанційного навчання, дослідженням програм, що застосовуються під час реалізації дистанційного навчання, вивченням методів викладання навчального матеріалу під час вказаної форми навчання займалися Беспалько В.П., Биков В.Ю., Жильцов О.Б, Жучок Ю.В., Кухаренко В.М., Лебедєва І.Л., Матвійчук О.В., Норік Л.О., Подласов С.О., Сальник І.В., Семеріков С.О., Сірик Е.П., Стрюк А.М., Хуторськой А.В. та інші вчені. Зокрема, в роботі (Подласов, Матвійчук \& Бригінець, 2017) проведено аналіз переваг і недоліків очного, змішаного і дистанційного навчання фізики студентів технічного університету. На основі проведеного аналізу авторами зазначеної роботи зроблено висновок про доцільність використання моделі перевернутого класу під час змішаного навчання фізики студентів технічних 3ВО. В роботі (Сальник \& Сірик, 2020) досліджено особливості проведення семінарських занять з фізики під час дистанційного навчання. Відзначено, що семінарське заняття активізує роботу студентів протягом семестру, мотивує їх працювати систематично, розширює межі самостійної роботи та змінює взаємовідносини в ланці викладач-студент, створюючи атмосферу співробітництва. В роботі (Жучок, 2020) відзначено, що дистанційна форма вивчення математичних дисциплін підвищує ефективність самостійної роботи студентів, надає нові можливості для творчості, а викладачам дозволяє реалізовувати принципово нові форми $\mathrm{i}$ методи навчання із застосуванням математичного моделювання явищ і процесів.

Проблема дослідження особливостей дистанційного навчання фізики та дисциплін математичного циклу $\epsilon$ актуальною і в закордонній педагогічній літературі. Зокрема, у роботі (Fauza, Ernidawati \& Syaflita, 2020) виділено ряд факторів, які негативно впливають на якість дистанційного вивчення фізики. Зокрема, велика кількість завдань на самостійне опрацювання, брак спілкування наживо студентів з викладачем, а також студентів між собою під час розгляду, обговорення та узагальнення нового матеріалу негативно впливають на якість фізичної освіти студентів. В роботі (Irfan, Kusumaningrum, Yulia \& Widodo, 2020) відзначенно, що викладачі математики не у повній мірі використовують можливості різних платформ під час реалізації дистанційного навчання; під час представлення нового матеріалу недостатньо використовують відео та анімації, обмежившись поданням презентацій у Power Point. B роботі (Li \& Lalani, 2020) відзначено, що в процесі онлайн-навчання можуть бути винайдені нові ефективні методи навчання, які будуть в подальшому використовуватися і під час організації освітнього процесу в очній формі по закінченню пандемії.

Однак, незважаючи на ряд робіт, в яких досліджено особливості дистанційного навчання фізики і дисциплін математичного циклу, в науково-педагогічній літературі не знайдено робіт, присвячених дослідженню ефективності дистанційного навчання фізики студентів технічних спеціальностей, що актуалізує мету представленої роботи.

Мета статті. Враховуючи вищезазначене, мета статі полягає у вивченні ефективності дистанційного навчання фізики студентів технічних спеціальностей очної форми навчання в умовах карантину.

\section{МЕТОДИ ДОСЛІДЖЕННЯ}

Для досягнення поставленої мети статті використовувалися наступні методи: аналіз і систематизація наукових публікацій, присвячених дослідженню особливостей дистанційного навчання фізики і дисциплін математичного циклу студентів, що навчаються в вітчизняних та закордонних зВо; аналіз, синтез, порівняння, систематизація, узагальнення під час обробки та обговорення результатів успішності студентів технічних спеціальностей Національного транспортного університету (НТУ) з фізики за результатами очного навчання протягом осіннього семестру 2019/20 навчального року (н/p) та дистанційного навчання протягом осіннього семестру 2020/21 н/p. Порівняння результатів успішності студентів 3 фізики проводилося в тих академічних групах, в яких протягом двох зазначених семестрів освітній процес здійснювали ті ж самі викладачі.

\section{РЕЗУЛЬТАТИ ДОСЛІДЖЕННЯ}

У зв'язку з введенням карантинних обмежень, спричинених тривалою пандемією COVID-19, починаючи 3 12 березня 2020 року освітній процес у всіх ЗВО України відбувається в дистанційній формі. В якості платформ, за допомогою яких здійснюється реалізація освітнього процесу з фізики в HTУ, використовуються Google Classroom i MOODLE. Зазначені платформи є одними з найбільш поширених серед тих, що використовуються під час дистанційного навчання (Zelinskiy, 2020). Автори представленої роботи переважно використовують платформу Google Classroom. Використовуючи можливості вказаної платформи, кожний викладач створив електронний навчальний курс фізики, що містить усі необхідні дидактичні матеріали: конспект лекцій, презентації Power Point, відеозаписи, навчальні посібники, методичні вказівки до виконання лабораторних робіт та організації самостійної роботи студентів тощо. Платформа Google Classroom дозволяє створювати різні види завдань для студентів, встановлювати строки здачі цих завдань. Вказана платформа надає можливість працювати із електронним журналом оцінок, який можуть переглядати студенти і при цьому мати повну інформацію про результати оцінювання їх поточної роботи, вчасно та невчасно виконані завдання. 
Для студентів очної форми навчання усі заняття з фізики (лекції, практичні та лабораторні) проводяться за фіксованим розкладом у режимі відео-конференцій Zoom або Google Meet, що створює можливість безпосереднього спілкування студентів з викладачем. Під час проведення лекцій з фізики студентам пропонується матеріал у вигляді презентацій Power Point або файлів у форматі PDF. Також під час лекцій використовуються відео, пов'язані з вивченням тих чи інших тем з курсу фізики. Всі питання, заплановані на лекцію, розглядаються в синхронному режимі часу, під час якого студенти мають можливість спілкуватися з викладачем, задавати питання. На практичних заняттях з фізики відбувається розв'язування задач, більш детально розглядаються деякі теоретичні питання, під час опанування яких у студентів виникли складнощі, проводиться поточний та модульний контроль, відбуваються доповіді і захисти рефератів, написання яких передбачено планом організації самостійної роботи студентів. Для поточного контролю знань студентів 3 фізики використовуються як традиційні форми контролю, тобто опитування, фізичний диктант, задачі, так і тестові завдання в Google Forms. Модульний контроль з фізики являє собою завдання в Google Forms, що має комплексний характер, тобто містить тестові теоретичні питання з варіантами відповідей, завдання на співставлення матеріалу, якісні і кількісні задачі з фізики. Лабораторні заняття, що заплановані програмою з фізики, також проводяться дистанційно у режимі відео-конференцій з використанням віртуальних лабораторних робіт, анімацій та відео, безпосередньо пов'язаних з темою лабораторної роботи. За необхідності, викладачі проводять онлайн-консультації зі студентами, використовуючи Google Classroom, додатки-месенджери Viber i Telegram, а також електронну пошту.

Для вивчення ефективності дистанційного навчання фізики було виконано порівняння успішності студентів із зазначеної дисципліни за результатами очного навчання протягом осіннього семестру 2019/20 н/р та дистанційного навчання протягом осіннього семестру 2020/21 н/р. Результати весняного семестру 2019/20 н/р не включено до розгляду, оскільки освітній процес протягом вказаного семестру відбувався як в очній (до карантину), так і в дистанційній формі (після введення карантину). Таким чином, було опрацьовано результати успішності з фізики студентів 7 академічних груп НТУ, що навчаються за спеціальностями 015 «Професійна освіта (транспорт)», 121 «Інженерія програмного забезпечення» (2 групи), 122 «Комп'ютерні науки» (2 групи), 131 «Прикладна механіка» та 193 «Геодезія та землеустрій». Загальна кількість студентів зазначених технічних спеціальностей, що складали іспити з фізики за результатами очного навчання (осінній семестр 2019/20 н/p) становила 131 особу, а за результатами дистанційного навчання (осінній семестр 2020/21 н/p) - 111 осіб. Освітній процес протягом двох зазначених семестрів у вказаних академічних групах здійснювали ті самі викладачі. Оцінювання знань з фізики студентів вказаних спеціальностей очної форми навчання здійснювалося за 100-бальною шкалою ЄКТС за накопичувальною системою, згідно з якою студенти протягом семестру за всі види навчальної діяльності могли отримати 60 балів, а під час складання підсумкового контролю (іспиту) - 40 балів. Відповідно до цього, сумі балів від 60 до 63 відповідає підсумкова оцінка «Задовільно» (Е), від 64 до 73 - «Задовільно» (D), від 74 до 81 - «Добре» (С), від 82 до 89 - «добре» (В), від 90 до 100 - «Відмінно» (А).

На рис. 1 представлено розподіл підсумкових оцінок з фізики студентів вищезазначених спеціальностей за результатами очного навчання протягом осіннього семестру 2019/20 н/р та дистанційного навчання протягом осіннього семестру 2020/21 н/p. На вказаному рисунку видно яка кількість студентів (у відсотках, оскільки в зазначених двох н/р іспити з фізики складала різна кількість осіб) із загальної кількості отримали ту чи іншу підсумкову оцінку з фізики за результатами очного та дистанційного навчання.

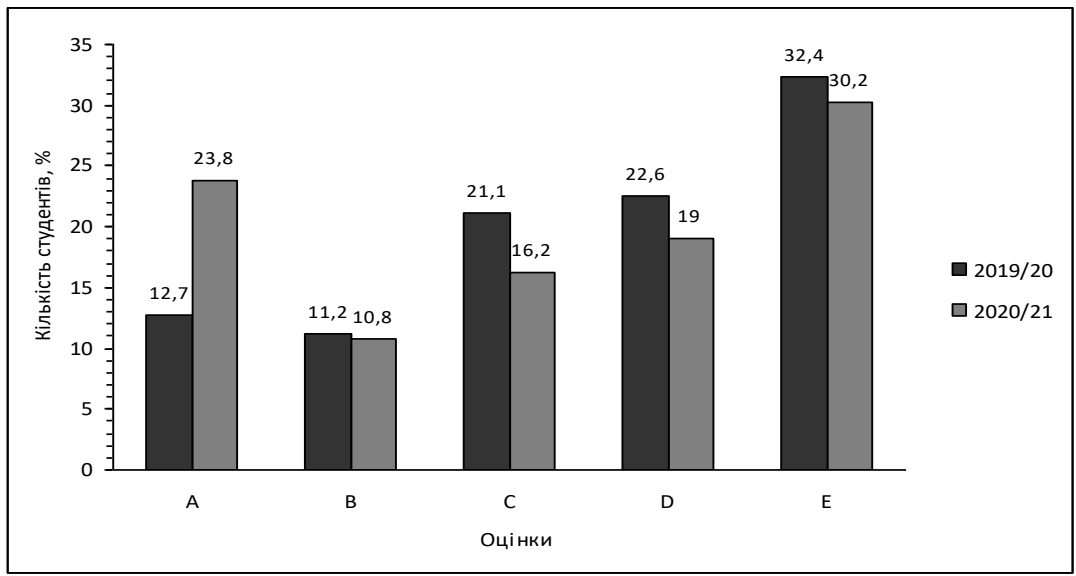

Рис. 1. Розподіл підсумкових оцінок з фізики за результатами очного навчання протягом осіннього семестру 2019/20 н/р та дистанційного навчання протягом осіннього семестру 2020/21 н/p

Виявилося, що розподіл підсумкових оцінок з фізики у двох зазначених семестрах досить відрізняється. Розбіжність, в першу чергу, проявилася в кількості отриманих підсумкових оцінок А. Зокрема, під час дистанційної форми навчання кількість студентів, що отримали з фізики підсумкову оцінку А, зросла на 11.1 \% у порівняні з кількістю студентів, що отримали А під час очної форми навчання. Щодо кількості підсумкових оцінок B, C, D і E, то розбіжність в їх кількості за два зазначені семестри виявилася не такою суттєвою. Зокрема, кількість студентів, що отримали підсумкові оцінки B, C, D і Е за результатами дистанційного вивчення фізики, систематично зменшилася на $0.4 \%, 4.9$ \%, 3.6 \% та 2.2 \% відповідно у порівнянні з кількістю студентів, що отримали зазначені оцінки за резульатами очного вивчення фізики. Рівень якості навчання, тобто відсоток студентів, що отримали підсумкові оцінки А, В і С, під час дистанційного навчання дорівнював $50.8 \%$, а під час очного навчання $-45 \%$. 


\section{ОБГОВОРЕННЯ}

Як видно з рис. 1, за результатами дистанційного навчання фізики можна виділити дві найбільші підгрупи студентів, що отримали підсумкові оцінки А (23.8 \%) та Е (30.2 \%) відповідно. Останнє означає, що студенти однієї 3 вказаних підгруп успішно виконували усі види завдань з фізики протягом семестру, в якому освітній процес було організовано в дистанційній формі, та, відповідно, отримали максимальну підсумкову оцінку А. Студенти іншої зазначеної підгрупи прикладали мінімальні зусилля під час дистанційного навчання та задовольнилися отриманням мінімальної підсумкової оцінки Е. Така тенденція спостерігалася в кожній академічній групі студентів. Отримані у даній роботі результати в цілому узгоджуються з результатами роботи (Лебедєва \& Норік, 2020), в якій відзначено, що в межах кожної академічної групи можна виділити дві найбільші сукупності студентів, які отримали максимальні та, відповідно, мінімальні підсумкові оцінки з дисциплін математичного циклу за результатами дистанційного навчання.

Необхідно відзначити, що дистанційне навчання фізики у сучасному форматі виявилося більш придатним для активних і організованих студентів. У той же час, студенти з низьким рівнем самоорганізації виявилися психологічно неготовими до дистанційного навчання та, як наслідок, отримали мінімальні підсумкові оцінки з фізики. Заборону відвідувати ЗВО через карантинні обмеження зазначені студенти сприйняли як привід не приділяти належної уваги освітньому процесу, помилково вважаючи карантин та дистанційне навчання такими собі канікулами. Ситуація, що склалася, остаточно дезорганізувала таких студентів, заважала їм зосередитися на навчанні. Разом з тим, щоб успішно навчатися в умовах проведення освітнього процесу в дистанційній формі, студентам необхідно прикладати більше зусиль і витрачати навіть більше часу, ніж під час очної форми навчання. Крім того, під час дистанційного навчання вирішального значення набуває самостійна робота студентів, що вимагає від них неабиякого рівня самоорганізації.

Таким чином, дистанційна форма навчання фізики студентів технічних спеціальностей НТУ як вимушена міра під час пандемії з достатньою ефективністю замінила очну форму навчання. В подальшому, на думку авторів, елементи дистанційної форми навчання можуть використовуватися як доповнення до очної форми. Однак, більш ефективною може бути змішана (гібридна) форма навчання (Кисельова, 2020), під час якої деякі види занять з фізики можуть проводитися дистанційно (наприклад, лекції), а інші - очно в аудиторіях 3ВО (наприклад, практичні і лабораторні заняття, консультації). Таке поєднання вказаних форм навчання надасть освітньому процесу достатньої гнучкості на випадок криз, подібних нинішній пандемії, а також відкриє нові можливості для усіх учасників освітнього процесу.

\section{ВИСНОВКИ ТА ПЕРСПЕКТИВИ ПОДАЛЬШОГО ДОСЛІДЖЕННЯ}

Таким чином, аналіз успішності студентів технічних спеціальностей НТУ з фізики за результатами очного та дистанційного навчання виявив суттєву розбіжність в розподілі підсумкових оцінок з вказаної дисципліни. Зокрема, за результатами дистанційного навчання фізики можна виділити дві найбільші підгрупи студентів, що отримали максимальні (А) та, відповідно, мінімальні (Е) підсумкові оцінки. Останнє спостерігалося в кожній академічній групі студентів. Рівень якості дистанційного навчання фізики, тобто відсоток студентів, що отримали підсумкові оцінки А, В і С, дорівнював 50.8 \% і виявився на 5.8 \% вищим, ніж за результатами очного навчання. Отже, дистанційна форма навчання фізики під час карантину з достатньою ефективністю замінила очну форму навчання. Однак, дистанційне навчання фізики у сучасному форматі виявилося менш придатним для студентів з низьким рівнем самоорганізації. Зазначені студенти виявилися психологічно неготовими до дистанційного навчання та, відповідно, отримали мінімальні підсумкові оцінки з фізики. В подальшому, на думку авторів, більш ефективною може бути змішана форма навчання фізики, яка сприятиме активізації освітнього процесу та підвищить мотивацію до навчання у студентів з низьким рівнем сомоорганізації. Останнє може сприяти більш глибокому засвоєнню студентами фізики та підвищити ефективність освітнього процесу в 3 ВО.

Наступну роботу планується присвятити встановленню ролі задач міжпредметного змісту в активізації освітнього процесу під час дистанційного проведення практичних занять з фізики і математики в технічному університеті.

\section{Список використаних джерел}

1. Андрущенко В. Освіта після пандемії. Міждисциплінарні дослідження складних систем, 2020. № 17. C. 5-13. DOI: 10.31392/iscs.2020.17.005.

2. Жучок Ю.В. Досвід впровадження дистанційного навчання математики в закладах вищої освіти. Фізикоматематична освіта, 2020. Вип. 3 (25). Ч. 2. С. 34-37. DOI: 10.31110/2413-1571-2020-025-3-022.

3. Іщенко Р.М., Ісаєнко Г.Л. Аналіз загальноосвітнього рівня предметної компетентності з фізики здобувачів вищої освіти технічного університету за результатами вхідного контролю. Збірник наукових праць Уманського державного педагогічного університету ім. Павла Тичини. Умань, 2020. Вип. 2. Ч. 2. С. 68-78.

4. Кисельова К. Як зміниться освіта після пандемії: 5 прогнозів світових експертів. Освіторія. Media, 2020. URL: https://osvitoria.media/experience/yak-zminytsya-osvita-pislya-pandemiyi-5-prognoziv-svitovyh-ekspertiv/ (Дата звернення: 20.04.2021).

5. Лебедєва І.Л., Норік Л.О. Ефективність е-learning студентів в умовах карантину на прикладі дисциплін математичного циклу. Фізико-математична освіта, 2020. Вип. 3 (25). Ч. 2. С. 93-100. DOI: 10.31110/2413-1571-2020-025-3-032.

6. Подласов С.О., Матвійчук О.В., Бригінець В.П. Елементи змішаного навчання фізики в технічному університеті. Інформаційні технології і засоби навчання, 2017. Том 61, № 5. C. 151-161. DOI: 10.33407/itlt.v61i5.1741.

7. Сальник І.В., Сірик Е.П. Підготовка та проведення семінарських занять з фізики в умовах дистанційного навчання. Наукові записки. Серія: Педагогічні науки, 2020. Вип. 189. С. 68-74. DOI: 10.36550/2415-7988-2020-1-189-68-74.

8. Fauza N., Ernidawati, Syaflita D. Difficulty analysis of physics students in learning online during pandemic COVID-19. Jurnal Geliga Sains (JGS): Jurnal Pendidikan Fisika, 2020. № 8 (1). P. 49-54. DOI: http://dx.doi.org/10.31258/jgs.8.1.49-54.

9. Irfan M., Kusumaningrum B., Yulia Y., Widodo S.A. Challenges during the pandemic: Use of e-learning in mathematics learning in higher education. Infinity: Journal of Mathematics Education, 2020. Vol. 9, № 2. P. 147-158. DOI: https://doi.org/10.22460/infinity.v9i2.p147-158.

10. Li C., Lalani F. The COVID-19 pandemic has changed education forever. This is how. World Economic Forum: Agenda, 29 April 
2020. URL: https://www.weforum.org/agenda/2020/04/coronavirus-education-global-covid19-online-digital-learning/ (Last accessed: 20.04.2021).

11. Zelinskiy S. Analysis of the possibilities of the MOODLE learning management system for organization of distance learning in the conditions of the university. Journal Science Rise: Pedagogical Education, 2020. № 5 (38). P. 33-36. DOI: 10.15587/25194984.2020.213100.

\section{References}

1. Andrushchenko, V. (2020). Osvita pislya pandemiyi [Post-pandemic education]. Mizhdystsyplinarni doslidzhennya skladnykh system - Interdisciplinary Studies of Complex Systems, 17, 5-13. DOI: 10.31392/iscs.2020.17.005 [in Ukrainian].

2. Zhuchok, Yul.V. (2020). Dosvid vprovadzhennya dystantsiynoho navchannya matematyky v zakladakh vyshchoyi osvity [Implementation features of the distance learning in mathematics in higher education institutions]. Fizyko-matematychna osvita - Physical and Mathematical Education, 3 (25), 2, 34-37. DOI: 10.31110/2413-1571-2020-025-3-022 [in Ukrainian].

3. Ishchenko, R.M. \& Isaienko, G.L. (2020). Analiz zahalnoosvitnoho rivnya predmetnoyi kompetentnosti z fizyky zdobuvachiv vyshchoyi osvity tekhnichnoho universytetu za rezultatamy vkhidnoho kontrolyu [Analysis of the general level of subject competence from physics of technical university students based on the results of the entrance control]. Zbirnyk naukovykh prats Umanskoho derzhavnoho pedahohichnoho universytetu im. Pavla Tychyny - Collection of scientific works of Uman state pedagogical university named after $P$. Tychyna, 2 (2), 68-78 [in Ukrainian].

4. Kyselova, K. (2020). Yak zminytsia osvita pislia pandemii: 5 prohnoziv svitovykh ekspertiv [How education will change after the pandemic: 5 forecasts of world experts]. Osvitoriia. Media - Osvitoria. Media. Retrieved from https://osvitoria.media/experience/yak-zminytsya-osvita-pislya-pandemiyi-5-prognoziv-svitovyh-ekspertiv/ [in Ukrainian].

5. Lebedeva, I.L. \& Norik, L.O. (2020). Efektyvnist e-learning studentiv v umovakh karantynu na prykladi dystsyplin matematychnoho tsyklu [The effectiveness of e-learning of students in quarantine conditions for the example of mathematical cycle disciplines]. Fizyko-matematychna osvita - Physical and Mathematical Education, 3 (25), 2, 93-100. DOI 10.31110/2413-1571-2020-025-3-032 [in Ukrainian].

6. Podlasov, S.O., Matviychuk, O.V. \& Briginets, V.P. (2017). Elementy zmishanoho navchannya fizyky $v$ tekhnichnomu universyteti [Elements of blended learning in studying physics in the technical university]. Informatsiyni tekhnolohiyi i zasoby navchannya - Information Technologies and Learning Tools, 61 (5), 151-161. DOI: 10.33407/itlt.v61i5.1741 [in Ukrainian].

7. Salnyk, I.V. \& Siryk, E.P. (2020). Pidhotovka ta provedennya seminarskykh zanyat z fizyky $v$ umovakh dystantsiynoho navchannya [Preparation and conducting of seminars on physics in the conditions of distance learning]. Naukovi zapysky. Seriya: Pedahohichni nauky - Scientific notes. Series: Pedagogical Sciences, 189, 68-74. DOI: 10.36550/2415-7988-2020-1189-68-74 [in Ukrainian].

8. Fauza, N., Ernidawati \& Syaflita, D. (2020). Difficulty analysis of physics students in learning online during pandemic COVID19. Jurnal Geliga Sains (JGS): Jurnal Pendidikan Fisika, 8 (1), 49-54. DOI: http://dx.doi.org/10.31258/jgs.8.1.49-54 [in English].

9. Irfan, M., Kusumaningrum, B., Yulia, Y. \& Widodo, S.A. (2020). Challenges during the pandemic: Use of e-learning in mathematics learning in higher education. Infinity: Journal of Mathematics Education, 9 (2), $147-158$. DOI: https://doi.org/10.22460/infinity.v9i2.p147-158 [in English].

10. Li, C. \& Lalani, F. (2020). The COVID-19 pandemic has changed education forever. This is how. World Economic Forum: Agenda, 29 April 2020. Retrieved from https://www.weforum.org/agenda/2020/04/coronavirus-education-global-covid19-onlinedigital-learning/ [in English].

11. Zelinskiy, S. (2020). Analysis of the possibilities of the MOODLE learning management system for organization of distance learning in the conditions of the university. Journal Science Rise: Pedagogical Education, 5 (38), 33-36. DOI: 10.15587/25194984.2020.213100 [in English].

\section{EFFECTIVENESS OF DISTANCE LEARNING OF PHYSICS OF TECHNICAL SPECIALTIES STUDENTS UNDER QUARANTINE CONDITIONS Ruslan Ishchenko, Iryna Gorbunovich National Transport University, Ukraine}

Abstract. Formulation of problem. Nowadays, distance learning is especially relevant when the educational process is carried out through the use of modern information and communication technologies. Physics is known to belong to the cycle of compulsory disciplines of natural sciences and mathematics, which is studied by students of technical specialties. At the same time, physics is traditionally one of the most difficult disciplines for most students. Accordingly, the study of the effectiveness of distance learning of physics by students of technical specialties in quarantine conditions is relevant.

Materials and methods. The results of students' success of technical specialties of the National Transport University in physics based on the results of full-time and distance learning were processed. The number of students was 242 people. To achieve the purpose of the work, the following methods are used: analysis and systematization - during the review of scientific publications on the chosen subject of research; analysis, synthesis, comparison, systematization, generalization - during the processing and discussion of the student achievements in physics based on the results of full-time and distance learning.

Results. In the presented work it is revealed that the distribution of final grades in physics based on the results of full-time and distance learning is quite different. In particular, according to the results of distance learning of physics, we can distinguish the two largest subgroups of students who received maximum $(A)$ and minimum $(E)$ final grades, correspondently. This trend is observed in each academic group of students. The level of quality of education, which is the percentage of students who received final grades $A, B$ and $C$ in physics, during distance learning is $50.8 \%$, that is $5.8 \%$ higher than during full-time education.

Conclusions. Thus, the distance learning of physics of technical specialties students during quarantine has replaced the full-time education with sufficient effectiveness. However, distance learning of physics in the modern format has proved to be less appropriate for students with a low level of self-organization. These students are psychologically unprepared for distance learning and, accordingly, receive minimal final grades in physics. In future, according to the authors, a mixed form of education of physics should be more effective.

Key words: distance learning, full-time education, physics course, final grades in physics, effectiveness of distance learning, students of technical specialties.

\section{(c) $)$ BY-NC-SA}

